\title{
Effect of Outdoor and Laboratorial Environment Science Activities on Middle School Students Understanding on Conservation
}

\author{
Ronaldo Angelini ${ }^{1, *}$, Juliana Simião Ferreira ${ }^{2,3}$, \\ Cecília Santiago do Carmo Araújo² \& Adriana Rosa Carvalho ${ }^{4}$
}

\author{
${ }^{1}$ Departamento de Engenharia Civil, Universidade Federal do Rio Grande do Norte - UFRN, Natal, RN, Brazil \\ ${ }^{2}$ Programa de Pós-graduação em Ecologia \& Evolução, Universidade Federal de Goiás - UFG, Goiânia, GO, Brazil \\ ${ }^{3}$ Laboratório de Educação Científica, Universidade Estadual de Goiás - UEG, Anápolis, GO, Brazil \\ ${ }^{4}$ Departamento de Botânica, Ecologia e Zoologia, Universidade Federal do Rio Grande do Norte - UFRN, Natal, RN, Brazil
}

\begin{abstract}
This work tested the learning in environmental science education activities involving middle school and undergraduate students. It was verified whether participation just once improved previous knowledge; if biodiversity understanding on the trail is more effective using manual guidance than using instructors' supervision, and if three consecutive activities increase understanding. Activities were conducted with three schools on the Brazilian savannah and consisted of oriented walk on the interpretive trail, aquatic insect sampling and identification under microscope. Daily activities increased student's knowledge, especially on second and third days of activities, when the subjects addressed were completely new for students. The oral guidance from the instructors was more efficient than the use of manual by children possibly because teaching/learning process is usually almost entirely supplied by teacher. The greatest gain was verified at the third day of activity reinforcing that consecutive activities can effectively improve the retention of understanding
\end{abstract}

Key words: Environmental Science Education, Brazilian Savannah, Cerrado, Conservation Biology.

\section{Introduction}

Since the 1970s, increasing environmental problems have slowly changed perceptions about the relationship between nature and economic growth (Mueller 2009). In an attempt to change awareness and attitude some communication strategies have been proposed, including changes at school curricula by the introduction on environmental science, conservation biology and environmental educational activities seeking for change students' behaviors and enlightens them about sustainable development (Pádua \& Jacobson 1999; Rennie 2007; Wyner \& Desalle 2010). In Brazil, those changes have been timid and ineffectual (Koury 2005) or speedy and on time (Curado \& Angelini 2006) and contemplates just a personal reconstruction of previously knowledge provided by the teacher or by the textbook (Gil-Pérez et al. 2002).Within the wider field of environmental science education it has been critical the lack

\footnotetext{
*Send correspondence to: Ronaldo Angelini Departamento de Engenharia Civil,

Universidade Federal do Rio Grande do Norte - UFRN,

CP 1524, CEP 59098-970, Natal, RN, Brasil

E-mail: angelini@ct.ufrn.br
}

of focus on the subjects of conservation and biodiversity and on substantive research on the public understand of biodiversity worldwide (Bride 2006). In addition, qualitative studies concerning biodiversity have failed to explore understandings (Bizerril 2004; Randler et al. 2005), to include features research on education programs (Brewer 2006) and to test procedures for achieve measurement-oriented approaches to educational activities (Jenkins 2001; Bride 2006). We propose here a distinct framework inviting middle school students to learn on environmental science in outdoor and laboratorial activities under undergraduate biologist students' tutelage. We aimed make environmental science education more accessible to children and their teachers and introduce concepts on conservation biology and biodiversity teaching for undergraduate students. Additionally all procedure was an experiment on environmental science education in which undergraduate students took part and also learnt environmental education in a scientific and quantitative viewpoint. At the experiment four consecutive environmental science education (ESE) activities were conducted. The goal was to test the three following hypotheses: i) participation 
in a single environmental and scientific education activity do not improve previous understanding about the visited environment; ii) the learning process while on the trail is more effective with the instructors' oral presentations than with use of a manual; iii) participation in three consecutive scientific and environmental activities contributes to a progressive increase in comprehension of the material covered.

\section{Material and Methods}

\section{Area of study}

The study was conducted in the Brazilian savannah that is a hotspot of global biodiversity in South America, with high rates of habitat conversion due to a recent expansion of soybean and sugar cane cultures and pasturelands (Myers et al. 2000; Marris 2005). The experiment was performed at the "Laboratório de Pesquisa Ecológica e Educação Científica" and on the Interpretive Trail of Environmental Education (ranging from savannahs and dense forest to open vegetation areas), called "Tatu Trail" both located at "Universidade Estadual de Goiás".

\section{Description of the activities}

The activities were developed in 2008 and 2009 with three middle schools from Anápolis, Goiás (hereafter designated as Schools I, II and III). One activity was conducted each week in the morning (from 8:00 AM to 11:00 AM) for one month, totaling four activities in consecutive weeks (see below). To work as monitors and accompany the children and their teachers in the activities, 25 undergraduate students in biology received specific training on the theme (biological conservation, Brazilian savannah biodiversity and aquatic macro-invertebrates ecology) and standardized teaching to minimize bias due to the instructor's performance. Previously at all activities, students answered a questionnaire (pre-test) of 10 objective questions concerning the subject of the day. After these activities, all children answered the same and respective questionnaire (now called post-test). The questionnaires were provides as Supplementary Material (S1)*.

In the first day the children were divided into two groups (treatments 1 and 2). Both groups were divided into an equal number of subgroups with five children each. Subgroups from group 1 walked the trail accompanied by two instructors. At previously defined stopping points, the instructors emphasized the factors that characterized the Brazilian savannah, the differences in vegetation, luminosity, humidity, biodiversity, soil and priorities for its conservation and encouraged the students to discuss hypotheses related to water pollution and degradation of the gallery forest and Barreiro stream. Subgroups from group 2 also walked the trail guided by the instructors and at the predetermined

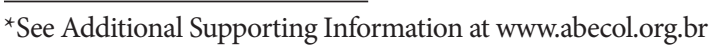

stopping points they were motivated to recognize the ecological characteristics of the phytophysiognomies and encouraged to formulate doubts and hypotheses according to their own observations using a manual that instructed them how.

At the second day, children attended a 30 minute lecture about macro-invertebrates as bio-indicators of environmental quality and they witnessed the sampling procedures for these organisms in the stream with preliminary observation in situ. At the third activity, children attended a 30 minute lecture about taxonomic classification and anatomic characteristics of macrobenthic invertebrates with special emphasis to the orders found during the $2^{\text {nd }}$ day of activity and that were either most sensitive to impact (Ephemeroptera, Plecoptera and Trichoptera) or most tolerant (Diptera and Oligochaeta) and to the linkage between ecosystem alteration and threatening for such tinny animals survival. After that they identified aquatic insects under stereoscopic microscopes. Finally, children were instructed to prepare a presentation to the last day of the activity about the content of the previous days. In groups or individually, the students gave 10 minutes oral presentations about one conclusion from the activities, using their choice of posters or drawings. At least one question on the subject presented was formulated for each group (or child). At the end of the presentations, the instructors reviewed the important subjects and underemphasized themes.

\section{Data analysis}

To test the hypothesis that one environmental scientific education activity increase students' biodiversity understanding, $t$-tests for dependent samples (paired) were conducted using the pre- and post-tests of the first three activities. To verify whether or not the manual is an effective tool in the learning process, a $t$-test for independent samples was created using the differences from the pre- and post-tests of the first activity for each student and then comparing the group 1 results (with instructors' assistance) to the group 2 results (with manual assistance). To test if the three activities promoted a progressive increase in comprehension of the content covered, an Analysis of Variance (ANOVA) was conducted using as a variable the difference between the pre- and post-tests of each student for each activity (treatment), which permitted an assessment of whether or not the tests among the activities were different (Zar 1996). To identify differences "a posteriori" among groups, Tukey's test was used. Levene's test to verify the homogeneity of the variances and test for normality of distribution were done as necessary.

For the last activity, a formal test was not available. The instructors, who met to discuss and note the most relevant facts from the student's presentations, evaluated the activity.

\section{Results}

One hundred and two children with mean of 11.7 years (standard deviation $=1.4$ ) participated of the study. Data 
for all tests were normality distributed at schools $(p \approx 0.3)$. Each of the three days of activity individually increased the student's understanding only from School III (Table 1). For School II, there was better student performance in the post-tests conducted on the second and third day of activity. School I had better performance in the second day. Analysis of the post-test performance of all the students (independent of school) showed that the students' understanding in respect to the subjects addressed improved on the second and third day of activities (Table 1).

The results comparing efficacy of manual to oral supervision by the instructors (for school II and III) demonstrated that the groups with instructors' help had better outcomes than groups with manual, but in only one of the schools the difference was significant (School II: $t$-value $=3.226$; d.f. $=36 ; \mathrm{p}<0.001$ and School III: $t$-value $=0.9$; d.f. $=17$; $\mathrm{p}=0.4)$. The test conducted with all the students indicated better performance of the group with instructors' help as well $(t$-value $=2.740$, d.f. $=55 ; \mathrm{p}=0.006)($ Figure 1$)$. There was homogeneity in the variances according to Levene's test (School II, $\mathrm{p}=0.50$, School III, $\mathrm{p}=0.45$ and both together $\mathrm{p}=0.12$ ).

Consecutive participation in three days of environmental science education activities increased the students' understanding concerning the content covered. The difference between the pre- and post-tests from the first to the third day of activities clearly increased $\left(\mathrm{SS}_{\text {group }}=213.94 ; \mathrm{F}=17.6\right.$; $\mathrm{p}<0.01$; d.f. $=2,185)$. There was no significant difference between the average of the tests during the first and second day of activities $(\mathrm{p}=0.07)$ for a posteriori Tukey's test. However, the findings from the first two days of activities differed from the last day ( $\mathrm{p}<0.001$ for both comparisons by Tukey), indicating that the third day of the ESE activity resulted in better student performance on the post-test. Levene's test confirmed variance's homogeneity $(p=0.47)$.

The qualitative observations from the last day, on which a formal test was not available, demonstrated that while some students had completely understood what was taught and the use of this knowledge for conservation, many students did not give good presentations, and others were too intimidated and afraid to participate in this activity, resulting in non attendance by School I.

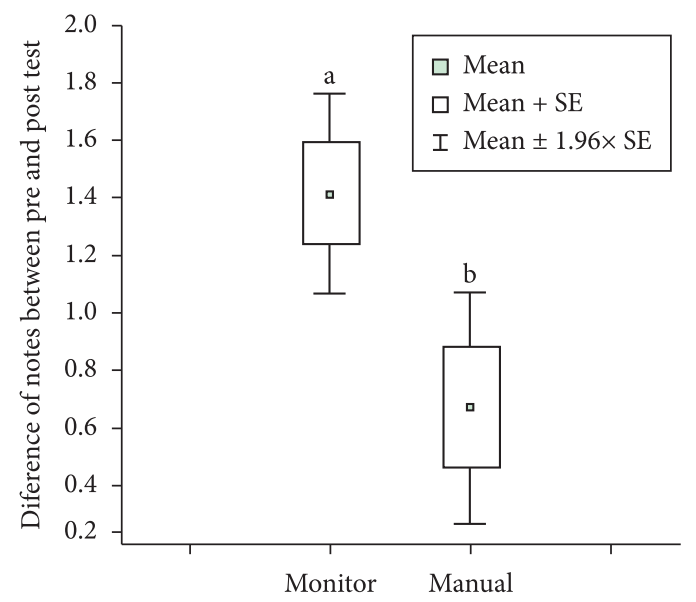

Figure 1. Means (and standard error - SE) from pre- and posttests between group of students assisted by oral instructions from monitors and group using manual in one activity of environmental science education in three schools (different letters means statistical difference).

Table 1. Mean, differences between means and paired t test results between pre- and post-tests from three days activities of environmental science education in three schools (standard deviation in brackets; d.f. = degrees freedom; bold p-values indicate significant $t$-values).

\begin{tabular}{ccccccc}
\hline School & $\begin{array}{c}\text { Mean } \\
\text { pre-test }\end{array}$ & $\begin{array}{c}\text { Mean } \\
\text { post-test }\end{array}$ & $\begin{array}{c}\text { Differences between } \\
\text { pre- and post-tests }\end{array}$ & t-value & p & d.f. \\
\hline School I & & & & & & \\
$1^{\text {st }}$ & $3.77(1.82)$ & $3.50(1.92)$ & $0.27(2.51)$ & 0.509 & 0.615 & 21 \\
$2^{\text {nd }}$ & $2.50(1.92)$ & $3.83(1.11)$ & $-1.33(1.96)$ & $\mathbf{2 . 9 9}$ & $\mathbf{0 . 0 0 5}$ & 30 \\
$3^{\text {rd }}$ & $2.20(1.61)$ & $2.26(1.58)$ & $-0.06(1.48)$ & 0.17 & 0.864 & 14 \\
School II & & & & & & \\
$1^{\text {st }}$ & $4.08(1.61)$ & $3.66(1.56)$ & $0.42(2.03)$ & 1.275 & 0.210 & 37 \\
$2^{\text {nd }}$ & $3.39(1.55)$ & $3.95(1.61)$ & $-0.55(1.67)$ & $\mathbf{2 . 0 3}$ & $\mathbf{0 . 0 4 8}$ & 37 \\
$3^{\text {rd }}$ & $3.97(1.51)$ & $5.03(1.48)$ & $-1.05(1.37)$ & $\mathbf{4 . 7 2}$ & $\mathbf{0 . 0 0 0}$ & 37 \\
School III & & & & & \\
$1^{\text {st }}$ & $4.63(1.92)$ & $6.15(1.42)$ & $-1.52(2.19)$ & $\mathbf{3 . 0 3 0}$ & $\mathbf{0 . 0 0 7}$ & 18 \\
$2^{\text {nd }}$ & $3.90(1.10)$ & $4.96(1.95)$ & $-1.06(1.98)$ & $\mathbf{2 . 9 9 0}$ & $\mathbf{0 . 0 0 5}$ & 30 \\
$3^{\text {rd }}$ & $3.87(2.06)$ & $6.75(1.88)$ & $-2.87(1.78)$ & $\mathbf{6 . 4 4 5}$ & $\mathbf{0 . 0 0 0}$ & 15 \\
All $^{\text {st }}$ & & & & & \\
$1^{\text {st }}$ & $4.13(1.75)$ & $4.21(1.96)$ & $-0.08(2.33)$ & 0.337 & 0.736 & 78 \\
$2^{\text {nd }}$ & $3.45(1.63)$ & $4.35(1.75)$ & $-0.86(1.84)$ & $\mathbf{2 . 0 3 7}$ & $\mathbf{0 . 0 4 8}$ & 37 \\
$3^{\text {rd }}$ & $3.56(1.80)$ & $4.82(2.20)$ & $-1.26(1.77)$ & $\mathbf{5 . 9 1 3}$ & $\mathbf{0 . 0 0 0}$ & 68 \\
\hline
\end{tabular}




\section{Discussion}

We aimed to provide straightforward methodology to involve middle school students and undergraduate students in environmental science education. The experimental design and testing procedure used were not completely original (Randler et al. 2005; Smith-Sebasto \& Carven 2006; Curado \& Angelini 2006) but provided quantitative approach and representative sampling. Daily activities performed increased student's knowledge especially on second and third days of activities, when the subjects addressed were completely new and any knowledge gain represented an increase in relation to their initial complete lack of knowledge about the subject. This reinforces the influence of a priori knowledge in student's learning (Randler et al. 2005) but also underlined that students have more knowledge on terrestrial ecosystem and its biodiversity than in aquatic environments.

The oral guidance from the instructors was more efficient than the use of the manual by children. This may be because field activities that required investigation and inductive reasoning from students were not part of the schools' curricula. As a result, students were not ready to observe neither concluded for themselves since teaching/learning process is almost entirely supplied by teacher (Gil-Pérez 2002). A second explanation could be that manual was badly prepared. Likewise, it is possible that the instructors were well trained and surpassed the instructions provided by the manual. However, the manual was prepared jointly with the instructors who had been participated in other science education activities. Thus, they used their previous experience to define the manual's structure. Because the manual and instructors were equivalent in the information contained or provided, the quality of the manual or the instructor should not influence students' performance. The greatest gain in knowledge was verified on the third day of activity because the students already had acquired knowledge from the previous week and the subject was entirely new (aquatic environments) and different from the first day (terrestrial ecosystem of Brazilian savannah), which was already known by the students. This confirmed that consecutive activities can effectively improve the retention of understanding on biodiversity and conservation issues and that a priori knowledge is fundamental for performance improvement on tests of this nature.

Additionally, the third day of activity introduced a new element of learning by using microscope which initiated the students to a new dimension of reality, thereby increasing both their curiosity and their learning. Furthermore it invokes the sense of performing a scientific task or behavior (Tobin 1990) that can positively influence students' attitudes and interests (Roth 1994; Hofstein \& Lunett 1982, 2003). Outcomes from the first three days of activity were different among schools and resulted in different performance on presentations in the last day of activity. Children from School II and III had good quality performance during presentations despite high differences among children from the same school. Nonetheless, School I, which had the worst performance in the prior days, did not attend the last activity given that those children were too fearful of make a presentation. This suggested that learning methods, teacher's involvement on the activities and teacher's qualification at each school may possibly has influenced the students learning since participants were children under homogeneous ages and coming from schools which have the same organizational structure, curricula and were located at similar suburbs.

Actually, some teachers who accompanied the students withdrew from observing the animals under the microscopes or walk the trail. Our finding is that it is imperative that some specific activity be prepared and designated for teachers and that their involvement and qualification be registered. This will allow participation from science teachers (Villani et al. 2009) by providing them with teaching aids to continue discussing the activity's themes in the classroom and awakening their interest in the subject. Usually, Brazilian policies for the teaching of science lack effective. As a result, local or even national conservation issues are barely considered while the economic importance of urbanization, agriculture and cattle ranching are underlined. Additionally, innovative teaching proposals are created but are not applied due to the structural deficiencies of the schools and teachers' disinterest or lack of training.

The study of Brazilian savannah ecology and biodiversity from a educational-scientific perspective (through observation, method and analysis of findings) is necessary and promising (Bizerril 2004). Our outcomes has proven that the concomitant use of an interpretive trail field activity and laboratory activities produce satisfactory performance in students understanding on biodiversity and conservation issues. It could provide an example of practice study that substantiates undergraduate students to assume their role as conservation educators in the next future, but under a scientific basis. Besides, we hope it could be replicated to test its suitability to the goals of conservation biology educators given that it requires mainly just knowledge and willingness from researchers and students at both sides.

\section{Acknowledgments}

To CNPq for funded the research (proc. 553174/2006-1), to Davi M.C.C. Alves and to undergraduate students of Biology at State University of Goiás for their assistance in the data sampling and to an anonymous referee.

\section{References}

Bizerril MXA, 2004. Children's perception of Brazilian cerrado biodiversity and landscapes. The Journal of Environmental Education, 35:47-58. http://dx.doi.org/10.3200/ JOEE.35.4.47-58

Brewer C, 2006. Translating data into meaning: education in conservation biology. Conservation 
Biology, 20:689-691. PMid:16909556. http://dx.doi. org/10.1111/j.1523-1739.2006.00467.x

Bride I, 2006. The conundrum of conservation education and the conservation mission. Conservation Biology, 20:1337-1339. PMid:17002747. http://dx.doi. org/10.1111/j.1523-1739.2006.00544.x

Curado PM \& Angelini R, 2006. Evaluation of environmental education activity in interpretive Trial three years after its accomplishment. Acta Scientiarum Biological Sciences, 28:395-401.

Gil-Pérez D et al., 2002. Defending Constructivism in Science Education. Science \& Education, 11:557-571. http://dx.doi. org/10.1023/A:1019639319987

Hofstein A \& Lunett VN, 1982. The role of the laboratory in science teaching: neglected aspects of research. Review of Educational Research, 52:201- 217.

Hofstein A \& Lunett VN, 2003. The Laboratory in science education: foundations for the twenty-first century. Science Education, 88:28-54.

Jenkins EW, 2001. Science Education as a Field of Research. Canadian Journal of Science, Mathematics and Technology Education, 1:9-21. http://dx.doi. org/10.1080/14926150109556448

Koury DMM, 2005. A critical view of the history and perspectives in the field of environmental education: study focusing on the Brazilian Situation. International Research in Geographical and Environmental Education, 14:160-172. http://dx.doi. org/10.1080/10382040508668348

Marris E, 2005. The forgotten ecosystem. Nature, 437:944-945. PMid:16222267. http://dx.doi.org/10.1038/437944a

Mueller MP, 2009. Educational reflections on the 'ecological crisis': ecojustice, environmentalism, and sustainability. Science \& Education, 18:1031-1056. http://dx.doi.org/10.1007/ s11191-008-9179-x
Myers N et al., 2000. Biodiversity hotspots for conservation priorities. Nature, 403:853-858. PMid:10706275. http:// dx.doi.org/10.1038/35002501

Pádua SM \& Jacobson SK, 1999. A comprehensive approach to an environmental education program in Brazil. The Journal of Environmental Education, 24:29-36.

Randler C, Ilg A \& Kern J, 2005. Cognitive and emotional evaluation of an amphibian conservation program for elementary school students. The Journal of Environmental Education, 37:43-52. http://dx.doi.org/10.3200/ JOEE.37.1.43-52

Rennie CJ, 2007. What counts as science education. Studies in Science Education, 43:135-143. http://dx.doi. org/10.1080/03057260708560231

Roth WM, 1994. Experimenting in a constructivist high school physics laboratory. Journal of Research in Science Teaching, 31:197- 223. http://dx.doi.org/10.1002/tea.3660310209

Smith-Sebasto NJ \& Carven L, 2006. Effects of pre- and posttrip activities associated with a residential environmental education experience on students' Attitudes Toward the Environment. The Journal of Environmental Education, 37:3-17. http://dx.doi.org/10.3200/JOEE.37.4.3-17

Tobin KG, 1990. Research on science laboratory activities. In pursuit of better questions and answers to improve learning. School Science and Mathematics, 90:403-418. http://dx.doi. org/10.1111/j.1949-8594.1990.tb17229.x

Villani A, Almeida JL \& Freitas D, 2009. Science teacher education in Brazil: 1950-2000. Science \& Education, 18:125-148. http://dx.doi.org/10.1007/s11191-007-9116-4

Wyner Y \& Desalle R, 2010. Taking the conservation biology perspective to secondary school classrooms. Conservation Biology, 24:649-654. PMid:20337673. http://dx.doi. org/10.1111/j.1523-1739.2010.01478.x

Zar JH, 1996. Biostatistical analysis. USA: Prentice Hall.

Received: November 2010

First Decision: December 2010 Accepted: February 2011 
